\title{
Labelling the salt content in foods: a useful tool in reducing sodium intake in Finland
}

\author{
Pirjo Pietinen*, Liisa M Valsta, Tero Hirvonen and Harri Sinkko \\ Department of Health Promotion and Chronic Disease Prevention, National Public Health Institute (KTL), \\ Mannerheimintie 166, 00300 Helsinki, Finland
}

Submitted 10 January 2007: Accepted 27 March 2007: First published online 3 July 2007

\begin{abstract}
Objective: To estimate the impact of choosing food products labelled either as low or high in salt on salt intake in the Finnish adult population.

Setting and subjects: The National FINDIET 2002 survey with 48-hour recalls from 2007 subjects aged 25-64 years. Sodium intake was calculated based on the Fineli ${ }^{\circledR}$ food composition database including the sodium content of natural and processed foods as well as the salt content of recipes. The distribution of salt intake was calculated in different ways: the present situation; assuming that all breads, cheeses, processed meat and fish, breakfast cereals and fat spreads consumed would be either 'lightly salted' or 'heavily salted' based on the current labelling practice; and, in addition, assuming that all foods would be prepared with $50 \%$ less or more salt.

Results: Excluding underreporters, the mean salt intake would be reduced by $1.8 \mathrm{~g}$ in men and by $1.0 \mathrm{~g}$ in women if the entire population were to choose lightly salted products and further by 2.5 and $1.8 \mathrm{~g}$, respectively, if also salt used in cooking were halved. Choosing heavily salted products would increase salt intake by $2.1 \mathrm{~g}$ in men and by $1.4 \mathrm{~g}$ in women. In the worst scenarios, salt intake would be further increased by $2.3 \mathrm{~g}$ in men and by $1.6 \mathrm{~g}$ in women.

Conclusions: These calculations show that the potential impact of labelling and giving consumers the possibility to choose products with less salt is of public health importance. In addition, strategies to reduce the salt content of all food groups are needed.
\end{abstract}

Keywords Sodium intake Salt labelling Salt reduction Nutrition survey
Salt intake has decreased in Finland since the late 1970s, thanks to systematic efforts including education of the public as well as the health care sector, involving the food industry and mass catering, and developing national legislation to help consumers to choose foods with less salt. Based on surveys on representative samples of adults between 1979 and 2002, 24-hour urinary sodium excretion decreased from over 220 to less than $170 \mathrm{mmol}$ among men and from nearly 180 to less than $130 \mathrm{mmol}$ among women ${ }^{1}$. Calculated as sodium chloride, salt intake has decreased from 13 to $10 \mathrm{~g}$ in men and from 10.5 to $7.6 \mathrm{~g}$ in women.

Discussion on how to reduce salt intake at the population level has been going on with the proposed strategies varying from voluntary stepwise reductions to labelling regulations ${ }^{2-4}$. All effective strategies are welcome since there is no easy way to reach the upper recommended salt intake level, which is less than $5 \mathrm{~g}$ day $^{-1}$ according to the World Health Organization ${ }^{5}$, and according to the Finnish National Nutrition Council $7 \mathrm{~g}$ for men and $6 \mathrm{~g}$ for women. The latter recommendations are based on the Nordic Nutrition Recommendations ${ }^{6}$.
In Finland, the labelling of salt has been determined by national regulations. Food categories, which are important sources of salt, must be labelled by marking the percentage of salt $(\mathrm{NaCl})$ by fresh weight of the product. National standards have been established for the categories of 'reduced salt' and 'heavily salted' in different foods. The aim in this analysis was to estimate how effective this labelling could maximally be, if the entire population were to choose available products with reduced salt content or heavily salted products also available in the market. In addition, we estimated the impacts of reducing salt in cooking by $50 \%$ or, likewise, increasing salt used in cooking by $50 \%$, which mimics the situation in Finland a few decades ago.

\section{Materials and methods}

We used the FINDIET 2002 study data to estimate the potential effect of using low-salt or high-salt foods on changing salt intake at the population level ${ }^{7}$. The FINDIET 2002 study was carried out as part of the FINRISK study, 
which monitors cardiovascular risk factors and is carried out every 5 years. A random sample of 12000 persons aged 25-64 years in six areas, stratified by sex, area and 10-year age group, was taken from the population register. The participation rate was $65 \%$. The FINDIET study was carried out in five areas: Helsinki area, Turku-Loimaa area, and the provinces of North Karelia, North Savo and Oulu. Of the invited subjects, $32 \%$ were randomly selected also to the dietary survey. The final sample of the dietary survey was 2007 subjects and the diet was assessed by 48-hour recall. Salt intake was calculated based on the National Food Composition Database Fineli ${ }^{\circledR}$ (www.fineli.fi), which has the natural sodium content of raw foods, the salt content of processed foods and the salt added in cooking in average recipes. This sodium/salt database was compiled in the early 1980s, validated against 24-hour urinary sodium excretion ${ }^{8}$ and since then has been updated regularly. In 2002, the sodium database was validated again? On average, sodium excretion was $97 \%$ of the calculated intake in men and $107 \%$ in women, reflecting greater underreporting in women. Thus, all the analyses were also carried out taking underreporting into account. Energy underreporters were excluded using $1.00 \times$ basal metabolic rate (BMR) as the cut-off point ${ }^{10}$. The percentage of underreporters was $32.7 \%$ in men and $39.9 \%$ in women.

Currently, foods can be marked as low-salt products if their salt content falls below a specified amount, or must be labelled as high-salt products if it exceeds a higher limit. These limits are as follows: $0.7 \%$ and $1.3 \%$ for bread, $1.2 \%$ and $1.8 \%$ for sausages, $0.7 \%$ and $1.4 \%$ for cheese, $1.2 \%$ and $1.7 \%$ for rye crisp bread and $1.0 \%$ and $1.7 \%$ for breakfast cereals. A low-salt limit has been set at $1.2 \%$ for processed meat, $1.0 \%$ for processed fish, $0.5 \%$ for soups, broths and sauces, and $0.5 \%$ for minced meat, liver, fish loaf and casserole foods without a high-salt limit. In addition, the old limits for butter and margarines, $1.0 \%$ and $2.0 \%$, are still voluntarily used by the manufacturers and, thus, they were also included in the calculations.
Salt intake was calculated in five different ways: (1) the current situation in 2002; (2) assuming that all the foods that could be purchased in lightly salted varieties, i.e. using the cut-off values listed above; (3) assuming that, in addition, salt used in cooking would also be reduced by 50\%; (4) assuming that all these regulated foods would be heavily salted using the following levels of salt: cheeses $1.7 \%$, breakfast cereals $2.4 \%$, processed meat $2.5 \%$ and processed fish $3.0 \%$, and the maximum level of normally salted products for the others; and (5) assuming that in addition to the heavily salted choices of the regulated foods, salt used in cooking would be 50\% higher than in the average recipes.

\section{Results}

The mean age of the subjects was 46 years in men and 45 years in women (Table 1). The basic composition of the diet was as follows: fat comprising 32.4-34.9\% of energy (men-women), protein 16.3-16.5\% and carbohydrates 45.6-49.6\%.

The calculated salt intake was $9.9 \mathrm{~g}$ in men and $6.8 \mathrm{~g}$ in women, when all persons were included (Table 2). If the entire population were to choose low-salt breads, cheeses, processed meat and fish, fat spreads, and breakfast cereals, then salt intake could be lowered by $1.5 \mathrm{~g}$ in men and by $0.9 \mathrm{~g}$ in women. If everybody was to select high-salt products, then salt intake would go up by $1.9 \mathrm{~g}$ in men and by $1.2 \mathrm{~g}$ in women. Thus, the potential difference between the low and the high alternatives would be $3.4 \mathrm{~g}$ in men and $2.9 \mathrm{~g}$ in women. If all prepared foods had a reduced salt content, the mean salt intake would go further down by $2.3 \mathrm{~g}$ in men and by $1.7 \mathrm{~g}$ in women.

When underreporters were excluded, the mean salt intake was $11.1 \mathrm{~g}$ in men and would go down to $9.5 \mathrm{~g}$ if all men chose lightly salted products and further down to

Table 1 Background information, mean (SD)

\begin{tabular}{|c|c|c|c|c|}
\hline & \multicolumn{2}{|r|}{ Men } & \multicolumn{2}{|r|}{ Women } \\
\hline & All $(n=912)$ & $\begin{array}{l}\text { Excluding underreporters* } \\
\qquad(n=614)\end{array}$ & All $(n=1095)$ & $\begin{array}{l}\text { Excluding underreporters } \\
\qquad(n=658)\end{array}$ \\
\hline Age & $46(11.3)$ & 45 (11.5) & $45(11.6)$ & $44(11.6)$ \\
\hline BMI $\left(\mathrm{kg} \mathrm{m}^{-2}\right)$ & $27.2(4.0)$ & $26.4(3.8)$ & $26.3(5.0)$ & $25.2(4.4)$ \\
\hline Education (years) & $11.6(3.8)$ & $11.5(3.8)$ & $11.3(3.8)$ & $11.4(3.7)$ \\
\hline Smokers (\%) & 25.6 & 25.4 & 22.2 & 20.9 \\
\hline Energy (kJ) & 9159 (2858) & $10472(2457)$ & $6619(2034)$ & $7808(1645)$ \\
\hline Protein (g) & $86(29)$ & $97(27)$ & $63(20)$ & $73(19)$ \\
\hline Cholesterol (mg) & $275(151)$ & $314(155)$ & $188(99)$ & $219(101)$ \\
\hline Fat $(\mathrm{g})$ & $87(36)$ & $101(35)$ & 59 (25) & $71(23)$ \\
\hline Sodium (g) & 3.93 (1.38) & $4.38(1.34)$ & $2.71(0.91)$ & $3.09(0.85)$ \\
\hline Potassium (g) & $4.00(1.20)$ & $4.37(1.15)$ & $3.18(0.90)$ & $3.54(0.84)$ \\
\hline Fat as $\%$ of energy & $35(8)$ & $36(8)$ & $32(7)$ & $33(7)$ \\
\hline Protein as $\%$ of energy & $16(4)$ & $16(3)$ & $17(4)$ & $16(3)$ \\
\hline Carbohydrate as \% of energy & $46(8)$ & $45(8)$ & $50(8)$ & $49(8)$ \\
\hline
\end{tabular}

SD - standard deviation; BMI - basal metabolic index; BMR - basal metabolic rate.

${ }^{*}$ Energy intake $>1.00 \times$ BMR. 
Table 2 Mean (SD) intake of salt from foods with different salt content (all subjects included)

\begin{tabular}{|c|c|c|c|c|c|c|c|c|c|c|}
\hline & \multicolumn{5}{|c|}{ Men } & \multicolumn{5}{|c|}{ Women } \\
\hline & Low salt2 & Low salt1 & Current situation & High salt1 & High salt2 & Low salt2 & Low salt1 & Current situation & High salt1 & High salt2 \\
\hline 1. Bread & $1.16(0.69)$ & $1.16(0.69)$ & $1.88(1.16)$ & $2.81(1.67)$ & $2.81(1.67)$ & $0.79(0.47)$ & $0.79(0.47)$ & $1.26(0.76)$ & $1.91(1.15)$ & $1.91(1.15)$ \\
\hline 2. Cheese & $0.27(0.27)$ & $0.27(0.27)$ & $0.44(0.46)$ & $0.74(0.72)$ & $0.74(0.72)$ & $0.23(0.22)$ & $0.23(0.22)$ & $0.37(0.36)$ & $0.62(0.57)$ & $0.62(0.57)$ \\
\hline 3. Processed meat & $0.53(0.78)$ & $0.53(0.78)$ & $0.82(1.17)$ & $1.16(1.67)$ & $1.16(1.67)$ & $0.18(0.34)$ & $0.18(0.34)$ & $0.29(0.55)$ & $0.40(0.75)$ & $0.40(0.75)$ \\
\hline 4. Processed fish & $0.05(0.18)$ & $0.05(0.18)$ & $0.20(0.95)$ & $0.26(1.07)$ & $0.26(1.07)$ & $0.02(0.10)$ & $0.02(0.10)$ & $0.07(0.33)$ & $0.11(0.41)$ & $0.11(0.41)$ \\
\hline 5. Breakfast cereals & $0.03(0.12)$ & $0.03(0.12)$ & $0.05(0.17)$ & $0.09(0.31)$ & $0.09(0.31)$ & $0.03(0.09)$ & $0.03(0.09)$ & $0.05(0.14)$ & $0.09(0.24)$ & $0.09(0.24)$ \\
\hline 6. Dietary fats & $0.24(0.22)$ & $0.24(0.22)$ & $0.41(0.42)$ & $0.60(0.54)$ & $0.60(0.54)$ & $0.13(0.14)$ & $0.13(0.14)$ & $0.22(0.25)$ & $0.34(0.36)$ & $0.34(0.36)$ \\
\hline Sum of intake from $1-6$ & $2.29(1.24)$ & $2.29(1.24)$ & $3.80(2.25)$ & $5.65(3.03)$ & $5.65(3.03)$ & $1.40(0.75)$ & $1.40(0.75)$ & $2.25(1.24)$ & $3.45(1.81)$ & $3.45(1.81)$ \\
\hline 7. Porridge & 0 & $0.36(0.77)$ & $0.36(0.77)$ & $0.36(0.77)$ & $0.55(1.16)$ & 0 & $0.33(0.65)$ & $0.33(0.65)$ & $0.33(0.65)$ & $0.49(0.98)$ \\
\hline 8. Vegetable dishes & $0.41(0.53)$ & $0.82(1.06)$ & $0.82(1.06)$ & $0.82(1.06)$ & $1.23(1.59)$ & $0.33(0.42)$ & $0.65(0.84)$ & $0.65(0.84)$ & $0.65(0.84)$ & $0.98(1.26)$ \\
\hline 9. Fish dishes & $0.33(0.66)$ & $0.66(1.33)$ & $0.66(1.33)$ & $0.66(1.33)$ & $0.99(1.99)$ & $0.23(0.44)$ & $0.46(0.89)$ & $0.46(0.89)$ & $0.46(0.89)$ & $0.69(1.33)$ \\
\hline 10. Meat dishes & $1.12(0.80)$ & $2.24(1.59)$ & $2.24(1.59)$ & $2.24(1.59)$ & $3.36(2.39)$ & $0.74(0.57)$ & $1.47(1.14)$ & $1.47(1.14)$ & $1.47(1.14)$ & $2.21(1.71)$ \\
\hline 11. Egg dishes & $0.06(0.18)$ & $0.12(0.36)$ & $0.12(0.36)$ & $0.12(0.36)$ & $0.19(0.54)$ & $0.03(0.13)$ & $0.03(0.13)$ & $0.03(0.13)$ & $0.03(0.13)$ & $0.10(0.40)$ \\
\hline Sum of intake from $7-11$ & $1.92(1.05)$ & $4.21(2.23)$ & $4.21(2.23)$ & $4.21(2.23)$ & $6.31(3.35)$ & $1.32(0.74)$ & $2.98(1.59)$ & $2.98(1.59)$ & $2.98(1.59)$ & $4.47(2.38)$ \\
\hline Sum of intake from 1-11 & $4.21(1.79)$ & $6.50(2.77)$ & $8.00(3.48)$ & $9.86(4.11)$ & $11.96(4.94)$ & $2.72(1.11)$ & $4.37(1.82)$ & $5.23(2.10)$ & $6.43(2.48)$ & $7.92(3.09)$ \\
\hline Total salt intake & $6.09(2.15)$ & $8.38(2.89)$ & $9.89(3.49)$ & $11.74(4.07)$ & $13.84(4.83)$ & $4.30(1.52)$ & $5.96(2.01)$ & $6.81(2.27)$ & $8.01(2.64)$ & $9.50(3.17)$ \\
\hline
\end{tabular}

SD - standard deviation.

Table 3 Mean (SD) intake of salt from foods with different salt content (underreporters excluded)

\begin{tabular}{|c|c|c|c|c|c|c|c|c|c|c|}
\hline & \multicolumn{5}{|c|}{ Men } & \multicolumn{5}{|c|}{ Women } \\
\hline & Low salt2 & Low salt1 & Current situation & High salt1 & High salt2 & Low salt2 & Low salt1 & Current situation & High salt1 & High salt2 \\
\hline 1. Bread & $1.29(0.72)$ & $1.29(0.72)$ & $2.10(1.23)$ & $3.13(1.76)$ & $3.13(1.76)$ & $0.93(0.51)$ & $0.93(0.51)$ & $1.48(0.83)$ & $2.24(1.25)$ & $2.24(1.25)$ \\
\hline 2. Cheese & $0.31(0.30)$ & $0.31(0.30)$ & $0.50(0.50)$ & $0.84(0.78)$ & $0.84(0.78)$ & $0.27(0.24)$ & $0.27(0.24)$ & $0.44(0.40)$ & $0.74(0.64)$ & $0.74(0.64)$ \\
\hline 3. Processed meat & $0.63(0.87)$ & $0.63(0.87)$ & $1.00(1.31)$ & $1.39(1.87)$ & $1.39(1.87)$ & $0.22(0.39)$ & $0.22(0.39)$ & $0.35(0.63)$ & $0.48(0.85)$ & $0.48(0.85)$ \\
\hline 4. Processed fish & $0.06(0.21)$ & $0.06(0.21)$ & $0.25(1.11)$ & $0.31(1.20)$ & $0.31(1.20)$ & $0.02(0.10)$ & $0.02(0.10)$ & $0.07(0.37)$ & $0.10(0.42)$ & $0.10(0.42)$ \\
\hline 5. Breakfast cereals & $0.04(0.13)$ & $0.04(0.13)$ & $0.06(0.19)$ & $0.10(0.34)$ & $0.10(0.34)$ & $0.04(0.10)$ & $0.04(0.10)$ & $0.05(0.15)$ & $0.10(0.27)$ & $0.10(0.27)$ \\
\hline 6. Dietary fats & $0.29(0.24)$ & $0.29(0.24)$ & $0.48(0.46)$ & $0.70(0.58)$ & $0.70(0.58)$ & $0.16(0.16)$ & $0.16(0.16)$ & $0.27(0.28)$ & $0.41(0.40)$ & $0.41(0.40)$ \\
\hline Sum of intake from $1-6$ & $2.62(1.29)$ & $2.62(1.29)$ & $4.37(2.38)$ & $6.47(3.15)$ & $6.47(3.15)$ & $1.65(0.80)$ & $1.65(0.80)$ & $2.66(1.32)$ & $4.06(1.90)$ & $4.06(1.90)$ \\
\hline 7. Porridge & 0 & $0.42(0.83)$ & $0.42(0.83)$ & $0.42(0.83)$ & $0.62(1.25)$ & 0 & $0.33(0.67)$ & $0.33(0.67)$ & $0.33(0.67)$ & $0.50(1.01)$ \\
\hline 8. Vegetable dishes & $0.42(0.56)$ & $0.85(1.13)$ & $0.85(1.13)$ & $0.85(1.13)$ & $1.28(1.69)$ & $0.34(0.44)$ & $0.68(0.87)$ & $0.68(0.87)$ & $0.68(0.87)$ & $1.01(1.31)$ \\
\hline 9. Fish dishes & $0.35(0.71)$ & $0.69(1.42)$ & $0.69(1.42)$ & $0.69(1.42)$ & $1.04(2.13)$ & $0.25(0.48)$ & $0.51(0.97)$ & $0.51(0.97)$ & $0.51(0.97)$ & $0.76(1.46)$ \\
\hline 10. Meat dishes & $1.24(0.82)$ & $2.47(1.65)$ & $2.47(1.65)$ & $2.47(1.65)$ & $3.71(2.47)$ & $0.83(0.61)$ & $1.67(1.21)$ & $1.67(1.21)$ & $1.67(1.21)$ & $2.50(1.82)$ \\
\hline 11. Egg dishes & $0.07(0.19)$ & $0.14(0.38)$ & $0.14(0.38)$ & $0.14(0.38)$ & $0.21(0.57)$ & $0.04(0.16)$ & $0.08(0.32)$ & $0.08(0.32)$ & $0.08(0.32)$ & $0.12(0.47)$ \\
\hline Sum of intake from $7-11$ & $2.08(1.13)$ & $4.57(2.32)$ & $4.57(2.32)$ & $4.57(2.32)$ & $6.85(3.58)$ & $1.47(0.80)$ & $3.26(1.69)$ & $3.26(1.69)$ & $3.26(1.69)$ & $4.89(2.58)$ \\
\hline Sum of intake from $1-11$ & $4.70(1.84)$ & $7.19(2.84)$ & $8.94(3.57)$ & $11.04(4.13)$ & $13.32(5.04)$ & $3.11(1.12)$ & $4.91(1.86)$ & $5.92(2.14)$ & $7.33(2.50)$ & $8.96(3.10)$ \\
\hline Total salt intake & $6.80(2.09)$ & $9.30(2.79)$ & $11.05(3.40)$ & $13.14(3.92)$ & $15.43(4.69)$ & $4.95(1.41)$ & $6.75(1.90)$ & $7.76(2.12)$ & $9.17(2.45)$ & $10.80(2.99)$ \\
\hline
\end{tabular}

SD - standard deviation. 

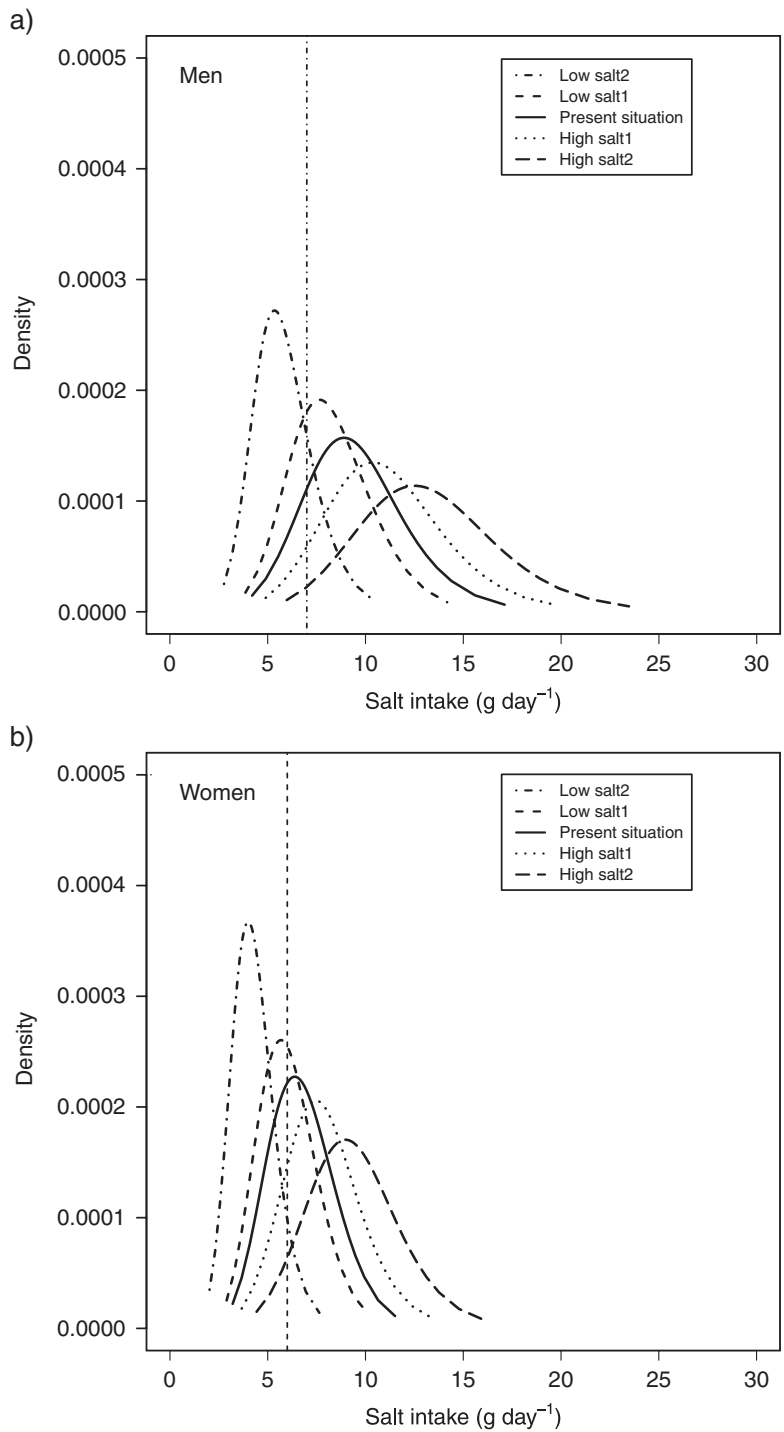

Fig. $1(a, b)$ The distribution of salt intake in the current situation, and assuming that all breads, cheeses, processed meat and fish, and breakfast cereals consumed were either low or high in salt based on the Finnish legislation on food labelling. The vertical line shows the upper recommended salt intake level, $7 \mathrm{~g} \mathrm{day}^{-1}$ for men and $6 \mathrm{~g} \mathrm{day}^{-1}$ for women

$6.8 \mathrm{~g}$ if also all prepared foods would have a lower salt content (Table 3). In women, the respective numbers are 7.8, 6.7 and $4.9 \mathrm{~g}$. If heavily salted products were chosen systematically, salt intake would be $13.1 \mathrm{~g}$ in men and $9.2 \mathrm{~g}$ in women. In the worst scenarios, the levels would be 15.4 and $10.8 \mathrm{~g}$, respectively.

The five different distribution curves in salt intake are shown in Fig. $1 \mathrm{a}$ and $\mathrm{b}$ for all and in Fig. $2 \mathrm{a}$ and $\mathrm{b}$ excluding underreporters. All the distribution curves would be shifted to the left with the consumption of lowsalt products and by reducing salt used in cooking. A shift to the right is seen if high-salt products were to be chosen and salt would be used heavily in cooking. a)

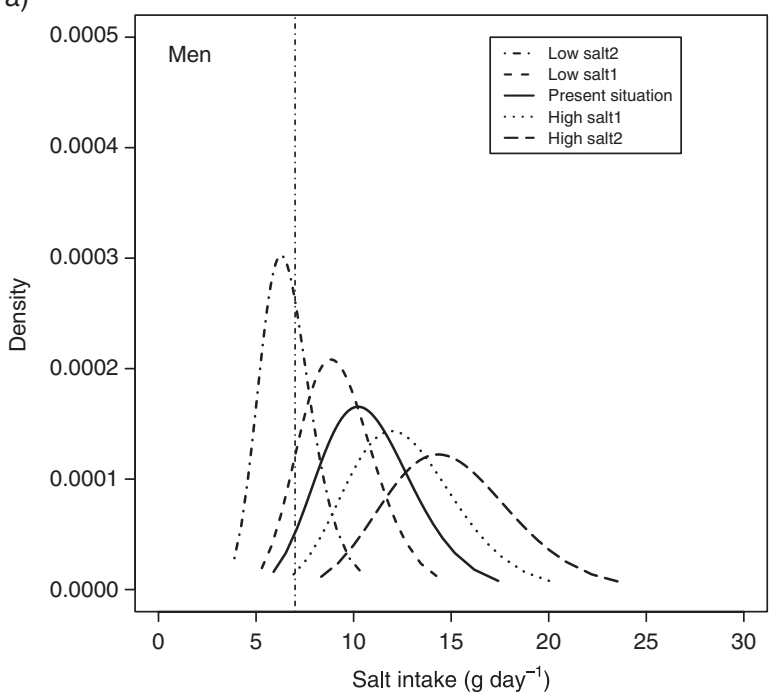

b)

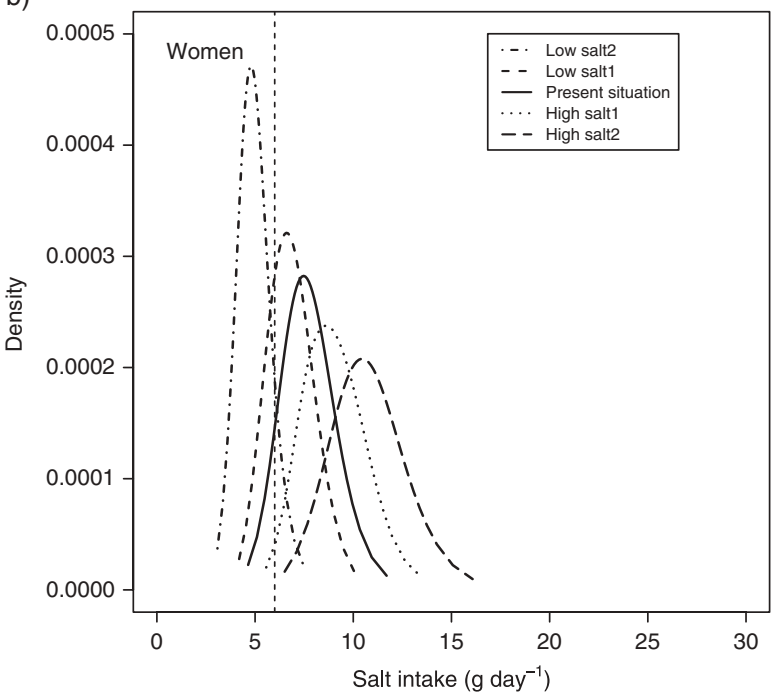

Fig. 2 ( $a, b)$ The distribution of salt intake excluding underreporters and assuming that all breads, cheeses, processed meat and fish, and breakfast cereals consumed were either low or high in salt based on the Finnish legislation on food labelling. The vertical line shows the upper recommended salt intake level, $7 \mathrm{~g} \mathrm{day}^{-1}$ for men and $6 \mathrm{~g} \mathrm{day}^{-1}$ for women

\section{Discussion}

This theoretical exercise compared different situations assuming that the whole population would use foods with reduced salt content, normally salted products or heavily salted products in order to show the maximum impact on salt intake that labelling foods might achieve. This analysis shows that labelling the salt content in foods could help to make a difference.

The favourable development in Finland is probably at least partly due to the national labelling legislation, which is a helpful tool in guiding consumers to choose products with less salt. When the legislation came into force, many heavily salted products, especially breads, disappeared 
from the market because the bakers did not want to label them as high-salt breads. On the other hand, a variety of products with reduced salt content emerged and have remained on the market. Labelling also contributed to a general discussion on the benefits of salt reduction. Even though labelling salt in fat spreads is no longer mandatory, the manufacturers continue to do it voluntarily and fats with the reduced salt label are widely available in the market.

Acceptable low/high salt limits depend on the food product. The maximum salt content of low-salt bread in Finland, $0.7 \%$ of fresh weight, has proven to be too low for most of the bakers and these low-salt breads represent only a small market. According to the bakers, the acceptable level seems to be about 1.0-1.1\% and breads with this salt content are widely available. However, as long as the highest limit for normally salted bread is $1.3 \%$, the majority of breads still have this salt content. Thus, lowering the maximum level for normally salted bread seems to be the most powerful way to further reduce the salt content of bread. Many European countries have only high-salt breads, over $1.3 \%$, available and, thus, reducing their salt content would represent a good opportunity for change.

Several countries have developed national programmes for reducing salt consumption in the population. The British Government's Food Standards Agency began a major campaign in 2003 to encourage food manufacturers to reduce added sodium, with a population recommendation that individuals consume less than $6 \mathrm{~g}$ of salt daily by $2010^{11}$. The Agency has published targets for specific food categories, which food processors can measure themselves against ${ }^{12}$. The food industry makes written commitments to reduce added salt.

In Ireland, the Food Safety Authority has also developed a programme for adults to a mean target of $6 \mathrm{gday}^{-1}$, and is seeking the cooperation of the food industry to achieve gradual and universal reductions in the salt content of processed and prepared foods ${ }^{13}$. Consideration is being given to the mandatory labelling of foods with salt content above a specific threshold as 'high salt' and the authority has recommended that methods be developed to monitor the salt content of processed food, as well as of food prepared in the food service sector.

In our analysis, excluding underreporters gives a more realistic picture of the present situation and the mean calculated intakes, $11.1 \mathrm{~g}$ in men and $7.8 \mathrm{~g}$ in women, are in line with the 24-hour urinary sodium ${ }^{1}$. The worst-case scenario in our calculations, $15.4 \mathrm{~g}$ in men and $10.8 \mathrm{~g}$ in women, mimics the situation in the 1970s when the mean salt intake was $14-15 \mathrm{~g}$ in men $^{14}$. We have succeeded to reduce salt intake to $10-11 \mathrm{~g}$ in men and to $7-8 \mathrm{~g}$ in women in over 20 years and the downward trend has been steady but slow. Thus, it is very optimistic to expect rapid changes at the population level. Our calculations based on both the selection of low-salt products and the imaginary situation where all foods would be prepared with 50\% less salt show that both of these measures are effective and needed in order to reach the aim of about $6 \mathrm{~g} \mathrm{day}^{-1}$. This means that besides labelling and regulating the salt content of processed foods, all cooked foods, whether prepared in the food service sector or at home, need to have a lower salt content. These measures need to run in parallel in the overall strategy so that people gradually get used to foods with less salt.

The public health impact of lowering salt intake in the population by just $2-3 \mathrm{~g}$ is significant based on several meta-analyses ${ }^{15-20}$. The most powerful evidence comes from two recent studies. In a Finnish cohort study, a $100 \mathrm{mmol}$ higher 24-hour sodium excretion increased the risk of coronary heart disease by $51 \%$, cardiovascular mortality by $45 \%$ and all-cause mortality by $26 \%{ }^{21}$. In a long-term follow-up of two intervention trials, people with prehypertension assigned to a sodium reduction intervention experienced a $25-30 \%$ lower risk of cardiovascular outcomes in the 10-15 years after the trial $^{22}$. Thus, all measures to reduce the salt content of foods gradually are welcome.

The results show that salt labelling has its limits but could be a useful component in an overall national strategy to reduce salt intake in the population. Its impact could obviously be increased by including more food groups and by focusing on the maximum limits of normally salted products rather than by making only low-salt products available. The effectiveness naturally depends also on how it is communicated to the consumers as well as on its ability to encourage the food industry to expand the variety of food products available with reduced salt content.

\section{Acknowledgements}

Source of funding: The study was funded by the Ministry of Social Affairs and Health.

Conflict of interest: None declared.

Authorship responsibilities: P.P., L.V. and T.H. have contributed to the study design. H.S. undertook the statistical analysis and produced the tables and figures for the manuscript. P.P. drafted the paper and L.V., T.H. and H.S. critically reviewed and contributed in finalising the manuscript.

\section{References}

1 Laatikainen T, Pietinen P, Valsta L, Sundvall J, Reinivuo H, Tuomilehto J. Sodium in the Finnish diet: 20-year trends in urinary sodium excretion among the adult population. European Journal of Clinical Nutrition 2006; 60: 965-70.

2 Young L, Swinburn B. Impact of the pick the tick food information programme on the salt content of food in New Zealand. Health Promotion International 2002; 17: 13-19.

3 Sharp D. Labelling salt in food: if yes, how? Lancet 2004; 364: 2079-80.

4 He FJ, MacGregor GA. Salt in food. Lancet 2006; 365: 844-5. 
5 World Health Organization (WHO). Diet, Nutrition and the Prevention of Chronic Diseases. Report of a Joint WHO/FAO Expert Consultation. WHO Technical Report Series No. 916. Geneva: WHO, 2003.

6 Nordic Nutrition Recommendations 2004. Integrating nutrition and physical activity. Nord 2004:13. Copenhagen: Nordic Council of Ministers, 2004.

7 Männistö S, Ovaskainen M-L, Vasta L, eds. The National Findiet 2002 Study. Publications of the National Public Health Institute B3/2003. Helsinki: Hakapain: OY, 2003.

8 Pietinen P. Estimating sodium intake from food composition data. Annals of Nutrition \& Metabolism 1982; 26: 90-9.

9 Reinivuo H, Valsta LM, Laatikainen T, Tuomilehto J, Pietinen P. Sodium in the Finnish diet: II Trends in dietary sodium intake and comparison between intake and 24-h excretion of sodium. European Journal of Clinical Nutrition 2006; 60: 1160-7.

10 Goldberg GR, Black AE, Jebb SA, Murgatroyd PR, Coward WA, Prentice AM. Critical evaluation of energy intake using fundamental principles of energy physiology: 1. Derivation of cut-off limits to identify under-recording. Journal of Clinical Nutrition 1991; 45: 569-81.

11 Food Standards Agency of Great Britain. Salt. Eat no more than $6 \mathrm{~g}$ a day [online]. Available at http://www.salt.gov. uk/no more than 6.shtml. Accessed 20 August 2006.

12 Food Standards Agency of Great Britain. Salt targets [online]. Available at http://www.food.gov.uk/multimedia/ pdfs/salttargetsapril106.pdf. Accessed 20 August 2006.

13 Food Safety Authority of Ireland. Salt and health: Review of the Scientific Evidence and Recommendations for Public Policy in Ireland [online]. Available at http:// www.fsai.ie/industry/salt. Accessed 5 January 2007.
14 Karvonen MJ, Punsar S. Sodium excretion and blood pressure of west and east Finns. Acta Medica Scandinavica 1977; 202: 501-7.

15 Law MR, Frost CD, Wald NJ. By how much does dietary salt reduction lower blood pressure? I - Analysis of observational data among populations. British Medical Journal 1991; 302: 811-15.

16 Law MR, Frost CD, Wald NJ. By how much does dietary salt reduction lower blood pressure? II - Analysis of observational data within populations. British Medical Journal 1991; 302: 815-18.

17 Law MR, Frost CD, Wald NJ. By how much does dietary salt reduction lower blood pressure? III - Analysis of data from trials within populations. British Medical Journal 1991; 302: 819-24.

18 Cutler JA, Follmann D, Allender PS. Randomized trials of sodium reduction: an overview. American Journal of Clinical Nutrition 2007; 65(Suppl.): 643S-51S.

19 He FJ, MacGregor GA. Effect of modest salt reduction on blood pressure: a meta-analysis of randomized trials. Implications for public health. Journal of Human Hypertension 2002; 16: 761-70.

20 He FJ, MacGregor GA. Effect of longer-term modest salt reduction on blood pressure. Cochrane Database of Systematic Reviews 2004; (3): CD004937.

21 Tuomilehto J, Jousilahti P, Rastenyte D, Moltchanov V, Tanskanen A, Pietinen $\mathrm{P}$, et al. Urinary sodium excretion and cardiovascular mortality in Finland: a prospective study. Lancet 2001; 357: 848-51.

22 Cook NR, Cutler JA, Obarzanek E, Buring JE, Rexrode KM, Kumanyika SK, et al. Long term effects of sodium reduction on cardiovascular disease outcomes. Observational followup of the trials of hypertension prevention (TOHP). British Medical Journal 2007; 334: 585-8. 